\title{
Propofol Anesthesia Is Reduced in Phospholipase C-Related Inactive Protein Type-1 Knockout Mice ${ }^{\text {『 }}$
}

\author{
Yoshikazu Nikaido, Tomonori Furukawa, Shuji Shimoyama, Junko Yamada, Keisuke Migita, \\ Kohei Koga, Tetsuya Kushikata, Kazuyoshi Hirota, Takashi Kanematsu, Masato Hirata, \\ and Shinya Ueno
}

Graduate School of Medicine (Y.N.), Department of Neurophysiology (Y.N., T.F., K.K., S.U.) and Department of Anesthesiology, Graduate School of Medicine (Y.N., T.Ku., K.H.), Research Center for Child Mental Development, Graduate School of Medicine (S.S., S.U.), and Department of Biomedical Sciences, Division of Medical Life Sciences, Graduate School of Health Sciences (J.Y.), Hirosaki University, Hirosaki, Japan; Department of Drug Informatics, Faculty of Pharmaceutical Sciences, Fukuoka University, Fukuoka, Japan (K.M.); Department of Cellular and Molecular Pharmacology, Division of Basic Life Sciences, Institute of Biomedical and Health Sciences, Hiroshima University, Hiroshima, Japan (T.Ka.); Laboratory of Molecular and Cellular Biochemistry, Faculty of Dental Science, Kyushu University, Fukuoka, Japan (M.H.); Fukuoka Dental College, Fukuoka, Japan (M.H.)

Received November 30, 2016; accepted April 4, 2017

\section{ABSTRACT}

The GABA type $A$ receptor $\left(\mathrm{GABA}_{A}-\mathrm{R}\right)$ is a major target of intravenous anesthetics. Phospholipase $\mathrm{C}$-related inactive protein type-1 (PRIP-1) is important in $\mathrm{GABA}_{A}-\mathrm{R}$ phosphorylation and membrane trafficking. In this study, we investigated the role of PRIP-1 in general anesthetic action. The anesthetic effects of propofol, etomidate, and pentobarbital were evaluated in wild-type and PRIP-1 knockout (PRIP-1 KO) mice by measuring the latency and duration of loss of righting reflex (LORR) and loss of tail-pinch withdrawal response (LTWR). The effect of pretreatment with okadaic acid $(\mathrm{OA})$, a protein phosphatase 1/2A inhibitor, on propofol- and etomidate-induced
LORR was also examined. PRIP-1 deficiency provided the reduction of LORR and LTWR induced by propofol but not by etomidate or pentobarbital, indicating that PRIP-1 could determine the potency of the anesthetic action of propofol. Pretreatment with $O A$ recovered the anesthetic potency induced by propofol in PRIP-1 KO mice. OA injection enhanced phosphorylation of cortical the $\mathrm{GABA}_{\mathrm{A}}-\mathrm{R} \beta 3$ subunit in PRIP-1 KO mice. These results suggest that PRIP-1-mediated $\mathrm{GABA}_{A}-\mathrm{R} \beta 3$ subunit phosphorylation might be involved in the general anesthetic action induced by propofol but not by etomidate or pentobarbital.

\section{Introduction}

Phospholipase C-related inactive protein type-1 (PRIP-1) is an inositol 1,4,5-trisphosphate binding protein, homologous to phospholipase C- $\delta 1$ but catalytically inactive (Kanematsu et al., 1992, 1996; Matsuda et al., 1998). PRIP-1 has various binding partners including GABA type A receptor $\left(\mathrm{GABA}_{\mathrm{A}}-\mathrm{R}\right)$ $\beta 1-3$ subunits (Terunuma et al., 2004), GABA $A_{A}-R$-associated protein (Kanematsu et al., 2002), protein phosphatases 1 and 2A (PP1 and PP2A) (Yoshimura et al., 2001; Kanematsu et al., 2006; Yanagihori et al., 2006), and Akt protein kinase (Fujii et al., 2010). PRIP-1 acts as a bridge between the $\gamma 2 \mathrm{GABA}_{\mathrm{A}}-\mathrm{R}$ subunit and $\mathrm{GABA}_{\mathrm{A}}-\mathrm{R}$-associated protein, and facilitates $\mathrm{GABA}_{\mathrm{A}}-\mathrm{R}$ membrane trafficking (Kanematsu et al., 2002;

This work was supported by a Hirosaki University Institutional Research grant; a Karoji Memorial Fund for Medical Research grant; the Japan Society for the Promotion of Science KAKENHI [Grants 23659735, 24229009, 25670663]; and the Ministry of Education, Culture, Sports, Science and Technology KAKENHI [Grants 23592242, 24659690].

https://doi.org/10.1124/jpet.116.239145.

S This article has supplemental material available at jpet.aspetjournals.org.
Mizokami et al., 2007). PRIP-1 binds to GABA $-\mathrm{R} \beta$ subunits as a scaffold protein of $\mathrm{PP} 1 / 2 \mathrm{~A}$, which regulate the phosphorylation level of $\beta$ subunits (Terunuma et al., 2004; Kanematsu et al., 2006, 2007; Yanagihori et al., 2006). PP1/2A dephosphorylate the $\beta$ subunit and induce receptor endocytosis mediated by clathrin adaptor protein (AP2) and clathrin (Comenencia-Ortiz et al., 2014). PRIP-1 inactivates PP1 activity and reduces PP2A activity (Terunuma et al., 2004; Kittler et al., 2005; Kanematsu et al., 2007; Sugiyama et al., 2012). Phosphorylation of PRIP-1 itself and lack of PRIP-1 liberates the active form of PP1 and further activates PP2A (Terunuma et al., 2004; Yanagihori et al., 2006; Sugiyama et al., 2012).

Our previous studies revealed that PRIP-1 knockout (PRIP-1 $K O)$ mice had reduced extrasynaptic GABAergic transmission (tonic inhibition) in the hippocampus, cerebral cortex, and spinal cord (Migita et al., 2011; Zhu et al., 2012). Furthermore, the effects of diazepam on GABAergic extrasynaptic transmission were markedly reduced in PRIP-1 KO mice compared with wild-type (WT) mice. Consequently, the anticonvulsant action of diazepam was suppressed in PRIP-1 KO mice

ABBREVIATIONS: ANOVA, analysis of variance; AP2, clathrin adaptor protein; AUC, area under the curve; GABA $A_{A}-R$, GABA type $A$ receptor; $K O$, knockout; LORR, loss of righting reflex; LTWR, loss of tail-pinch withdrawal response; MPE, maximal possible effect; OA, okadaic acid; PP, protein phosphatase; PRIP-1, phospholipase C-related inactive protein type-1; TAS, total anesthesia score; WT, wild type. 
(Zhu et al., 2012). However, it remains unknown how PRIP-1 affects anesthetic action through the regulation of GABAergic transmission.

Most intravenous anesthetics enhance the inhibitory action of $\mathrm{GABA}_{\mathrm{A}}-\mathrm{R}$ (Rudolph and Antkowiak, 2004). Extrasynaptic GABAergic transmission is more likely to contribute to general anesthesia than synaptic transmission (Semyanov et al., 2004; Bieda and MacIver, 2004; Belelli et al., 2009; Bieda et al., 2009; Kubo et al., 2009; Herd et al., 2014). The phosphorylation state of $\mathrm{GABA}_{\mathrm{A}}-\mathrm{R}$ is thought to determine its localization and activity in the synaptic or extrasynaptic membrane (Terunuma et al., 2004; Abramian et al., 2010; Comenencia-Ortiz et al., 2014).

We investigated whether PRIP-1 deficiency influences the anesthetic action of three intravenous anesthetics-propofol, etomidate, and pentobarbital-and whether PRIP-1-mediated $\mathrm{GABA}_{\mathrm{A}}-\mathrm{R}$ phosphorylation states are involved in their anesthetic action.

\section{Materials and Methods}

Animals. We used adult male PRIP-1 KO $(n=223)$ and WT $(\mathrm{C} 57 \mathrm{BL} / 6 ; n=184)$ mice, aged $12-18$ weeks and weighing $25-35 \mathrm{~g}$. Animals were group-housed at $24 \pm 2^{\circ} \mathrm{C}$ under a 12-hour light/dark cycle (lights on at 8:00 AM), and food and water were available ad libitum. The experimental procedures used in this study complied with the guidelines for animal research issued by the Physiologic Society of Japan and Hirosaki University School of Medicine, and all efforts were made to minimize the number of animals used and their suffering.

Drugs. For behavioral studies, mice received propofol (Maruishi Pharmaceuticals, Osaka, Japan), etomidate (Tokyo Chemical Industry, Tokyo, Japan), or pentobarbital (Somunopentyl; Kyoritsu Seiyaku, Tokyo, Japan) intraperitoneally (i.p.) at a volume of $10 \mu \mathrm{l} / \mathrm{g}$ body weight. The vehicle for propofol and etomidate was $20 \%$ intralipid fluid solution (Fresenius Kabi, Tokyo, Japan). Pentobarbital was diluted with $0.9 \%$ saline (Otsuka Pharmaceuticals, Tokyo, Japan). PP1/2A inhibitor okadaic acid (OA) sodium salt (Wako Pure Chemical Industries, Tokyo, Japan) was dissolved in $0.9 \%$ saline $(0.01 \mathrm{mg} / \mathrm{ml})$ and injected (10 $\mu \mathrm{l} / \mathrm{g}$ body weight i.p.) 30 minutes before administration of propofol or etomidate. The dose of OA used in this study did not cause cyanosis, dyspnea, or diarrhea (Tubaro et al., 2003).

No hypnotic or analgesic effects were observed after intralipid or saline injection in either genotype ( $n=4$ per group; data not shown). For Western blotting, mice were injected $(10 \mu \mathrm{l} / \mathrm{g}$ body weight i.p.) with $\mathrm{OA}(0.01 \mathrm{mg} / \mathrm{ml})$ or saline. Other animals received $\mathrm{OA}(1 \mathrm{pg} / 5 \mu \mathrm{l})$ or vehicle (saline, $5 \mu \mathrm{L}$ ) intracerebroventricularly (i.c.v.) under $1 \%-3 \%$ isoflurane (Escain; Pfizer, Tokyo, Japan) for general anesthesia and lidocaine (Xylocaine jelly 2\%; AstraZeneca, Osaka, Japan) for local surface anesthesia, as described previously elsewhere (Maeda et al., 2005). Thirty minutes after the i.p. injection, or 25 minutes after the i.c.v. injection, the mice were euthanized with pentobarbital (150 mg/kg i.p.), and the brain tissue was collected ( $n=3$ per group).

Behavioral Analysis. Loss of righting reflex (LORR) was used to measure the hypnotic effect of the anesthetic agents. Immediately after drug injection, each animal was placed in a chamber $(20 \times 28 \times$ $15 \mathrm{~cm}$ ) with an electric heat pad, and the righting reflex was assessed every 2 minutes for a maximum of 2 hours. Anesthesia was evaluated using the following scoring system (Irifune et al., 2003): 0, normal righting reflex; 1, righting within 2 seconds; 2 , righting latency 2-10 seconds; 3, no righting within 10 seconds. Anesthetic scores were determined every 2 minutes as the median of three trials. Total anesthetic score (TAS) was the sum of all anesthetic scores used to evaluate anesthetic efficacy. Sensitivity to anesthetics was expressed as the percentage of animals to be given a score of 3 (\% LORR). The time from drug administration to a score of 3 was considered the latency to LORR, and the duration of LORR was measured as the time between a score of 3 and a subsequent score of 2 . When a score of 1 was followed by two consecutive scores of 0 , the mice were considered to have recovered from anesthesia.

Loss of tail-pinch withdrawal response (LTWR) assay was performed to evaluate immobilization, which is known to be the anesthetic-induced ablation of the supraspinal nociceptive response to noxious stimuli. A surgical clip $\left(125 \mathrm{~g} / \mathrm{cm}^{2}\right.$, micro-serrefine no. 18055-04; Fine Science Tools, Foster City, CA) was placed at the base of an animal's tail for 10 seconds (cutoff time) at 15 minutes after anesthetic administration. The nociceptive response was measured by the time (test latency) when the mouse showed any response to the tail-pinch.

Baseline nociceptive response (baseline latency) was measured 30 minutes before drug injection. To estimate LTWR, the percentage of maximal possible effect (\% MPE) was evaluated using this formula: $\% \mathrm{MPE}=100 \times($ Test latency - Baseline latency $) /($ Cutoff time Baseline latency). The magnitude of LTWR was assessed by the area under the \% MPE versus time curve (area under the curve [AUC]) using the trapezoidal method (Maeda et al., 2005).

Western Blotting. Immediately after euthanasia, each mouse was perfused with ice-cold phosphate-buffered saline and the brain removed (Maeda et al., 2005; Zhu et al., 2012). Thick coronal sections of the frontal cortex were made at the level of the striatum (Paxinos and Franklin, 2001). Total protein extracts and Western blotting were performed as described elsewhere (Ozaki et al., 2012). The crude membrane fraction was prepared using a previous method with modification (Goebel-Goody et al., 2009; Garcão et al., 2014). Tissue was homogenized in ice-cold homogenization buffer ( $\mathrm{pH}$ 6.0) containing the following (in $\mathrm{mM}$ ): 320 sucrose, 20 Tris-HCl, $0.1 \mathrm{CaCl}_{2}$, $1 \mathrm{MgCl}_{2}$, cOmplete Protease Inhibitor Cocktail EDTA-free (Roche Diagnostics, Mannheim, Germany), and PhosSTOP Phosphatase Inhibitor Cocktail (Roche Diagnostics). The homogenate was centrifuged at $1000 \mathrm{~g}$ for 10 minutes, and then supernatant was further centrifuged at $10,000 \mathrm{~g}$ for 20 minutes to obtain the crude membrane fraction. The precipitate was dissolved in homogenization buffer containing $1 \%$ SDS and saved as the crude membrane fraction. Solubilized proteins were isolated from the frontal cortex and equal amounts of protein was separated by SDS-PAGE and transferred electrophoretically to a polyvinylidene difluoride membrane (Bio-Rad Laboratories, Hercules, CA).

Membranes were incubated with the following primary antibodies: anti-GABA $A_{A}-R \beta 2,3$ subunit antibody (Millipore, Temecula, CA); anti$\mathrm{GABA}_{\mathrm{A}}-\mathrm{R} \beta 3$ subunit antibody (Millipore); anti-GABA $\mathrm{A}-\mathrm{R} \beta 3$ phosphoSer408/409 antibody (PhosphoSolutions, Aurora, CO); anti- $\beta$-actin antibody (Abcam, Cambridge, MA); or anti-gephyrin antibody (Synaptic Systems, Göttingen, Germany). Membranes were washed with Tween 20-phosphate-buffered saline and incubated with horseradish peroxidase-conjugated goat anti-rabbit or rabbit anti-mouse IgG (Dako, Cambridge, UK). Immunoreactive signals were developed with an enhanced chemiluminescence Western blotting detection kit (GE Healthcare, Princeton, NJ) and quantified using a luminescent image analyzer (LAS-4000; Fujifilm, Tokyo, Japan). Band intensities were measured using ImageJ software (http://rsbweb.nih.gov/ij/).

Statistics. To estimate the median effective dose $\left(\mathrm{ED}_{50}\right)$ with $95 \%$ confidence, probit analysis was performed on the LORR doseresponse data for each anesthetic using the generalized linear model function (glm) with probit link function and dose predict function (dose.p) in the R-package MASS (Venables and Ripley, 2002; $\mathrm{R}$ Core Team, 2016). TAS, expressed as the median (range), was analyzed using the Mann-Whitney $U$ test. Data for the latency and duration of LORR and percentage with MPE of LTWR are expressed as mean \pm S.E.M.

To compare the effects of anesthetics on LORR and LTWR between genotypes, unpaired $t$ tests were performed. One-way analysis of variance (ANOVA) with a post hoc Tukey's test was used to determine the effects of OA on LORR induced by propofol or etomidate. Unpaired $t$ tests were used to assess the effects of OA on membrane expression 
and phosphorylation levels of the $\mathrm{GABA}_{\mathrm{A}}-\mathrm{R} \beta 3$ subunit. All statistical analyses were performed with $\mathrm{R}$ version 3.3.2 ( $\mathrm{R}$ Core Team, 2016). $P<0.05$ was considered statistically significant.

To estimate effect size as a benchmark for assessing the magnitude of differences between WT and PRIP-1 KO mice, Cohen's $d$ value for unpaired $t$ tests and Mann-Whitney $U$ tests, and Cohen's $f$ value for one-way ANOVA were computed using the test function in the R-package compute.es (Del Re, 2013). Cohen defined a small effect as $d=0.20$ or $f=0.10$, medium effect as $d=0.50$ or $f=0.25$, and a large effect as $d=0.80$ or $f=0.40$ (Cohen, 1992).

\section{Results}

Effect of PRIP-1 Deficiency on Sensitivity to Propofol, Etomidate, and Pentobarbital. First, we determined the $\mathrm{ED}_{50}$ for the number of mice showing LORR (\% LORR) with each anesthetic in WT and PRIP-1 KO mice. Table 1 summarizes LORR and TAS values at each dose for propofol, etomidate, and pentobarbital in PRIP-1 KO and WT mice. The doseresponse curve of \% LORR for each anesthetic is shown in Fig. 1. The $\mathrm{ED}_{50}$ of propofol in PRIP-1 KO mice was greater than that in WT mice (Fig. 1A, left panel). Propofol at the maximum dose of $140 \mathrm{mg} / \mathrm{kg}$ could not evoke LORR in all PRIP-1 KO mice tested. TAS for propofol in PRIP-1 KO mice was lower than that in WT mice (Table 1). There were no differences between genotypes for etomidate or pentobarbital $\mathrm{ED}_{50}$ values (Fig. 1, B and C, left panels).

Effect of PRIP-1 Deficiency on Induction and Maintenance of Hypnosis Induced by Propofol, Etomidate, and Pentobarbital. Because the highest dose of each anesthetic in this study was most effective at inducing a stable LORR occurrence and/or increased anesthetic scores for PRIP-1 $K O$ mice (Table 1; temporal anesthetic score changes after each anesthetic treatment are shown in Supplemental Figs. 1-3), we estimated the hypnotic potency of these anesthetics at the highest doses by measuring the latency and duration of LORR. Latency to LORR in PRIP-1 KO mice after injection of propofol (140 mg/kg i.p.) was significantly longer than that in WT mice (Fig. 1A, right panel). The duration of propofolinduced LORR in PRIP-1 KO mice was significantly shorter than that in WT mice. There were no significant differences in latency or duration of LORR between genotypes after etomidate (30 mg/kg i.p.; Fig. 1B, right panel) or pentobarbital $(40 \mathrm{mg} / \mathrm{kg}$ i.p.; Fig. 1C, right panel) administration.

Effect of PRIP-1 Deficiency on Immobilization Produced by Propofol, Etomidate, and Pentobarbital. LTWR was examined to evaluate the immobilizing potency of each anesthetic in WT and PRIP-1 KO mice. PRIP-1 KO mice showed attenuation of propofol $(140 \mathrm{mg} / \mathrm{kg}$ i.p.)evoked LTWR (\% MPE) in comparison with WT mice (Fig. 2A). The magnitude of propofol-induced LTWR (AUC) in PRIP-1 KO mice was significantly smaller than that in WT mice. There were no significant differences between genotypes in \% MPE and AUC of LTWR produced by etomidate $(30 \mathrm{mg} / \mathrm{kg}$ i.p.; Fig. $2 \mathrm{~B})$ or pentobarbital $(40 \mathrm{mg} / \mathrm{kg}$ i.p.; Fig. 2C).

Hypnotic Effect of Propofol in PRIP-1 KO Mice Was Rescued by OA Pretreatment. PRIP-1 possesses a binding site for $\mathrm{GABA}_{\mathrm{A}}-\mathrm{R}$ subunits and $\mathrm{PP} 1 / 2 \mathrm{~A}$, and functionally regulates not only trafficking but also phosphorylation of $\mathrm{GABA}_{\mathrm{A}}-\mathrm{R}$. We have electrophysiologically demonstrated dysfunction of the extrasynaptic $\mathrm{GABA}_{\mathrm{A}}-\mathrm{R}$ response in PRIP-1 KO mice (Migita et al., 2011; Zhu et al., 2012). Therefore, we examined whether PP1/2A inhibitor rescued the perturbed anesthetic action of propofol. Pretreatment with PP1/2A inhibitor OA before propofol administration reduced LORR latency and prolonged LORR duration in PRIP-1 KO mice (Fig. 3A), but did not do the same with etomidate administration (Fig. 3B). The TAS of propofol ( $140 \mathrm{mg} / \mathrm{kg}$ i.p.), but not etomidate (30 $\mathrm{mg} / \mathrm{kg}$ i.p.), increased after OA pretreatment $(0.1 \mathrm{mg} / \mathrm{kg}$ i.p. $)$ in PRIP-1 KO mice (Table 2). OA pretreatment did not alter these values in WT mice. These results indicated that recovery of the hypnotic effect of propofol in PRIP-1 KO mice was provided by phosphorylation of $\mathrm{GABA}_{\mathrm{A}}-\mathrm{R}$.

TABLE 1

Effects of anesthetics on TAS and LORR in WT and PRIP-1 KO mice

\begin{tabular}{|c|c|c|c|c|c|c|}
\hline \multirow{2}{*}{ Anesthetic } & \multirow{2}{*}{ Dose } & \multicolumn{2}{|r|}{ WT } & \multicolumn{2}{|c|}{ PRIP-1 KO } & \multirow{2}{*}{ Effect Size $^{c}$} \\
\hline & & $n^{a}$ & $\mathrm{TAS}^{b}$ & $n^{a}$ & TAS $^{b}$ & \\
\hline \multirow{7}{*}{ Propofol } & $m g / k g$ & & & & & \\
\hline & 40 & $0 / 6$ & $0(0-3)$ & $0 / 6$ & $0(0-21)$ & 0.40 \\
\hline & 60 & $3 / 7$ & $1(0-25)$ & $0 / 7$ & $0(0-3)$ & 1.03 \\
\hline & 80 & $4 / 6$ & $36.5(0-43)$ & $1 / 6$ & $16.5(0-24)^{d}$ & 1.51 \\
\hline & 100 & $6 / 7$ & $52(0-110)$ & $6 / 14$ & $7.5(0-45)^{d}$ & 1.31 \\
\hline & 120 & $7 / 7$ & $97(14-161)$ & $7 / 13$ & $21(6-127)^{d}$ & 0.92 \\
\hline & 140 & $7 / 7$ & $71(54-149)$ & $10 / 14$ & $29(6-79)^{d}$ & 1.87 \\
\hline \multirow[t]{5}{*}{ Etomidate } & 5 & $0 / 6$ & $0(0-1)$ & $0 / 6$ & $0(0-3)$ & 0.07 \\
\hline & 8 & $2 / 10$ & $2.5(0-81)$ & $2 / 11$ & $0(0-41)$ & 0.67 \\
\hline & 10 & $7 / 8$ & $21(0-78)$ & $8 / 9$ & $17(0-86)$ & 0.21 \\
\hline & 20 & $6 / 6$ & $47(36-147)$ & $6 / 6$ & $48(19-101)$ & 0.05 \\
\hline & 30 & $9 / 9$ & $125(82-180)$ & $10 / 10$ & $107.5(58-180)$ & 0.72 \\
\hline \multirow[t]{5}{*}{ Pentobarbital } & 10 & $0 / 6$ & $0(0-0)$ & $0 / 6$ & $3(0-15)$ & 0.77 \\
\hline & 15 & $2 / 6$ & $11.5(0-29)$ & $2 / 5$ & $12(6-68)$ & 0.64 \\
\hline & 20 & $5 / 7$ & $15(5-22)$ & $5 / 7$ & $15(3-43)$ & 0.17 \\
\hline & 30 & $6 / 6$ & $38.5(24-46)$ & $9 / 9$ & $30(18-43)$ & 0.82 \\
\hline & 40 & $6 / 6$ & $88(41-136)$ & $6 / 6$ & $71(42-164)$ & 0.28 \\
\hline
\end{tabular}

${ }^{a}$ Denominators represent the number of animals tested in each group. Numerators represent animals that showed LORR.

${ }^{b}$ TAS express the sum of anesthetic scores as median (range).

${ }^{c}$ Effect size (Cohen's $d$ ) for TAS compared with WT mice with the same treatment.

${ }^{d} P<0.05$ versus WT mice with the same treatment (Mann-Whitney $U$ test). 
A Propofol

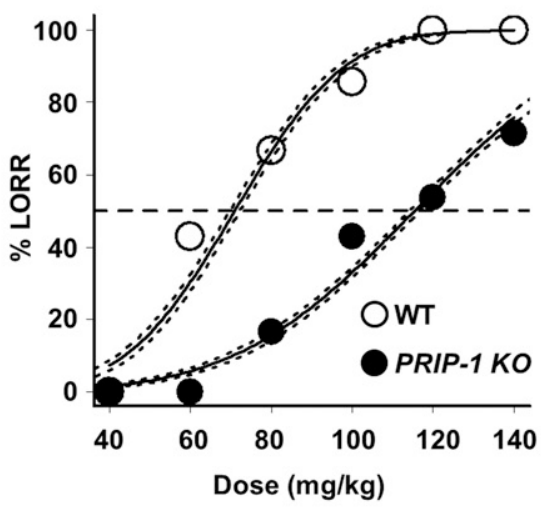

B Etomidate

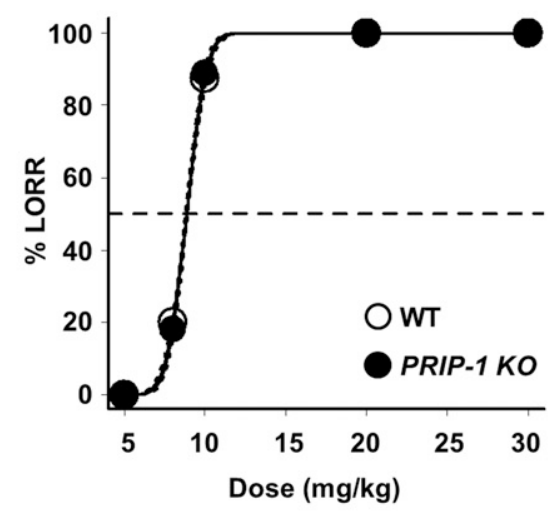

C Pentobarbital

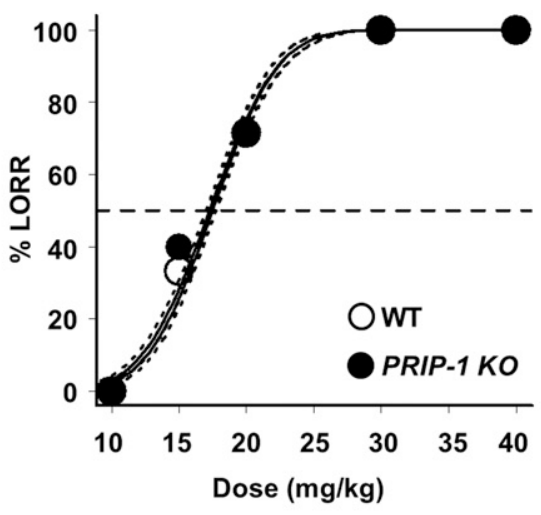

Propofol $140 \mathrm{mg} / \mathrm{kg}$ i.p.
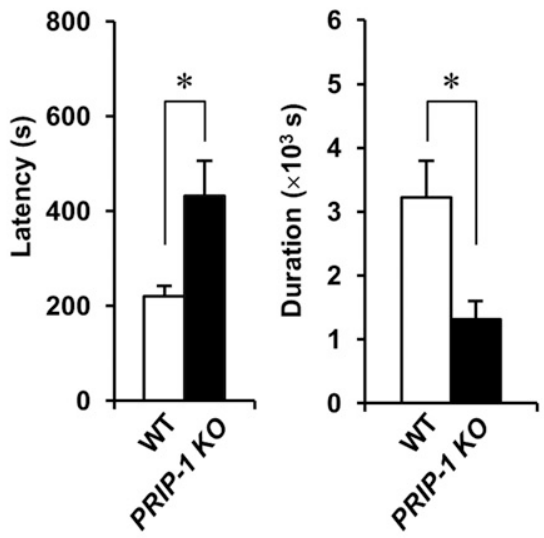

Etomidate $30 \mathrm{mg} / \mathrm{kg}$ i.p.
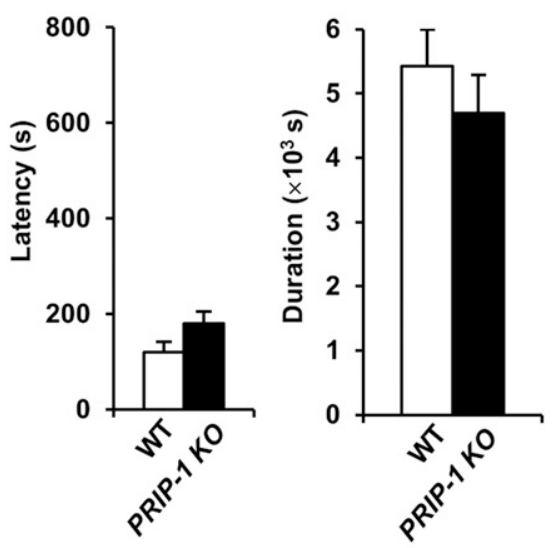

Pentobarbital $40 \mathrm{mg} / \mathrm{kg}$ i.p.
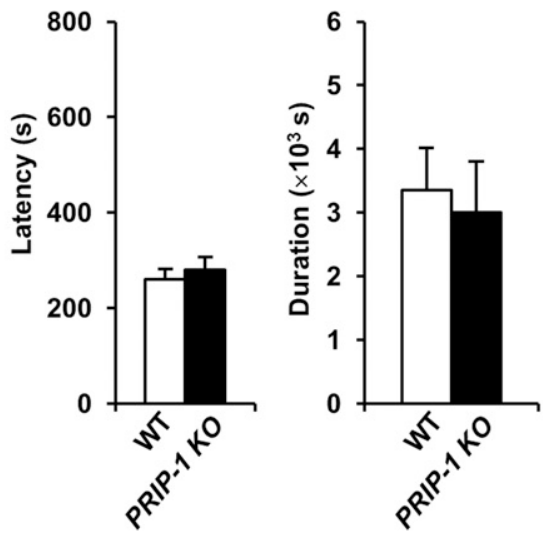

Fig. 1. Effect of PRIP-1 deficit on hypnosis produced by propofol, etomidate, and pentobarbital. (A) Dose-response curves for LORR induced by propofol in WT and PRIP-1 KO mice. Probit analysis was used to fit curves of $\mathrm{ED}_{50}$ values (solid lines) and 95\% confidence intervals (dashed curves). $\mathrm{ED}_{50}$ values were $71.0 \mathrm{mg} / \mathrm{kg}$ (95\% confidence interval, $69.8-72.2 \mathrm{mg} / \mathrm{kg}$ ) in WT mice and $115 \mathrm{mg} / \mathrm{kg}$ $(114-117 \mathrm{mg} / \mathrm{kg})$ in PRIP-1 KO mice. Significant prolongation of latency to LORR was observed with administration of propofol $(140 \mathrm{mg} / \mathrm{kg}$ i.p.) in PRIP-1 KO mice (unpaired $t$ test: $\mathrm{t}_{15}=2.95, P<$ 0.05 , Cohen's $d=1.30$ ). PRIP-1 KO mice emerged from propofol-induced LORR significantly earlier than WT mice $\left(\mathrm{t}_{15}=3.16, P<0.05, d=1.80\right)$. (B) $\mathrm{ED}_{50}$ values of etomidate were $8.85 \mathrm{mg} / \mathrm{kg}$ $(8.78-8.91 \mathrm{mg} / \mathrm{kg})$ in WT mice and $8.85 \mathrm{mg} / \mathrm{kg}$ $(8.79-8.92 \mathrm{mg} / \mathrm{kg}$ ) in PRIP-1 KO mice, and (C) those of pentobarbital were $17.5 \mathrm{mg} / \mathrm{kg}(17.2-17.8 \mathrm{mg} / \mathrm{kg})$ in WT mice and $17.2 \mathrm{mg} / \mathrm{kg}(16.9-17.5 \mathrm{mg} / \mathrm{kg})$ in PRIP-1 KO mice. There were no significant differences in response to etomidate $(30 \mathrm{mg} / \mathrm{kg}$ i.p. $)$ or pentobarbital $(40 \mathrm{mg} / \mathrm{kg}$ i.p.) between WT and PRIP-1 KO mice (etomidate: latency, $\mathrm{t}_{17}=1.76$, $P>0.05, d=0.81$; duration, $\mathrm{t}_{17}=0.94, P>0.05$ $d=0.43 ;$ pentobarbital: latency, $\mathrm{t}_{10}=0.68, P>0.05$, $d=0.36$; duration, $\left.\mathrm{t}_{10}=0.41, P>0.05, d=0.22\right)$. Group $n \geq 5$ mice. $* P<0.05$ versus WT mice. Data are mean \pm S.E.M.
Effect of OA on Protein Expression of GABA $\mathbf{A}_{A}-\mathrm{R} \beta 2,3$ Subunits and the Phosphorylated $\beta 3$ Subunit in PRIP-1 KO Mice. The GABA $\mathrm{A}^{-\mathrm{R}} \beta 3$ subunit is thought to be a common target of propofol and etomidate. Therefore, we performed Western blotting to evaluate the effect of OA pretreatment on phosphorylation states for the cortical $\mathrm{GABA}_{\mathrm{A}}-\mathrm{R} \beta 3$ subunit. There was less phosphorylation of the $\mathrm{GABA}_{\mathrm{A}}-\mathrm{R} \beta 3$ subunit in the frontal cortex of PRIP-1 $K O$ mice than in WT mice (Fig. 4A). Both i.p. and i.c.v. administration of $\mathrm{OA}$ enhanced $\mathrm{GABA}_{\mathrm{A}}-\mathrm{R} \beta 3$ subunit phosphorylation without affecting overall levels of the $\beta 2,3$ subunit in PRIP-1 KO mice. In addition, these OA treatments induced enhancement of $\beta 3$ subunit membrane expression and phosphorylation levels (Fig. 4B). The $\beta 3$ subunit membrane expression levels in PRIP-1 KO mice were lower than those in WT mice after saline treatment (Fig. 4C). After i.p. or i.c.v. OA treatments, $\beta 3$ subunit membrane expression increased in both genotypes. Phosphorylation levels of the 
A Propofol $140 \mathrm{mg} / \mathrm{kg}$ i.p.

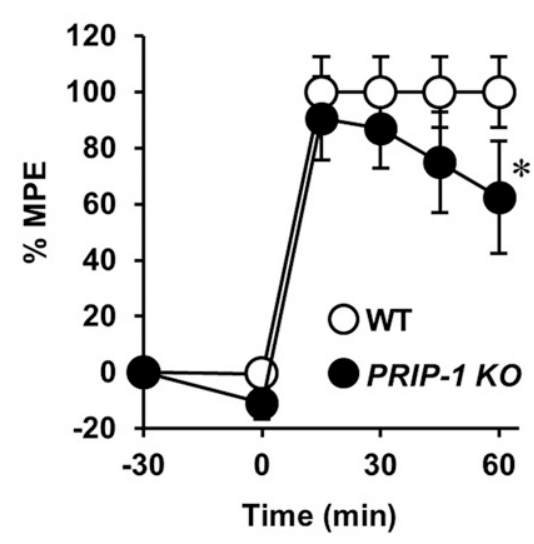

B Etomidate $30 \mathrm{mg} / \mathrm{kg}$ i.p.

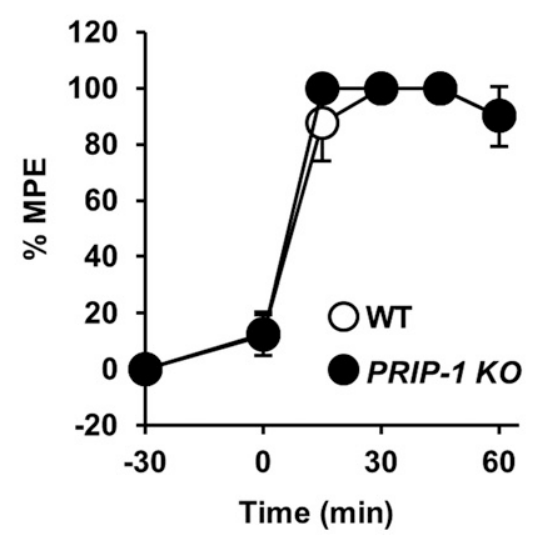

C Pentobarbital $40 \mathrm{mg} / \mathrm{kg}$ i.p.

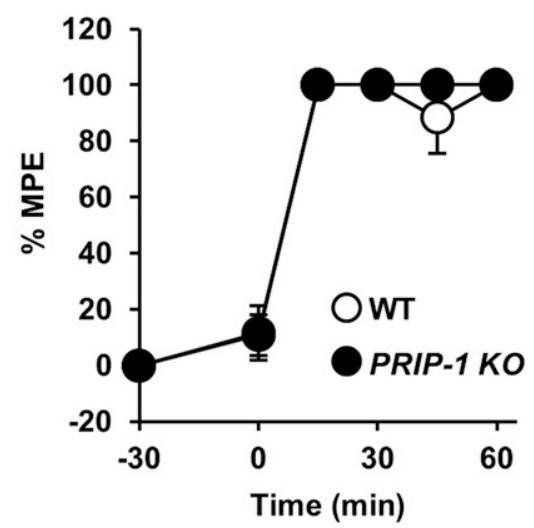

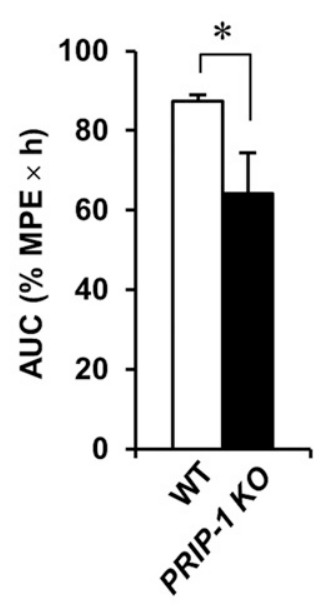
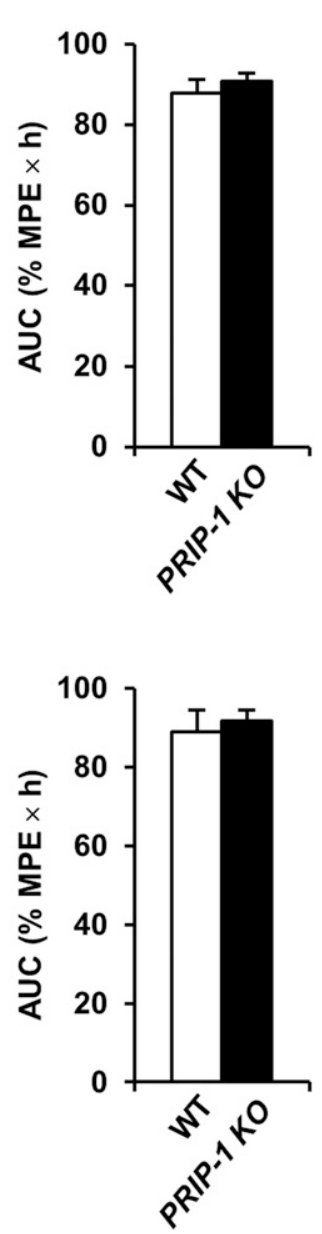

A OA $0.1 \mathrm{mg} / \mathrm{kg}$ i.p. + Propofol $140 \mathrm{mg} / \mathrm{kg}$ i.p.
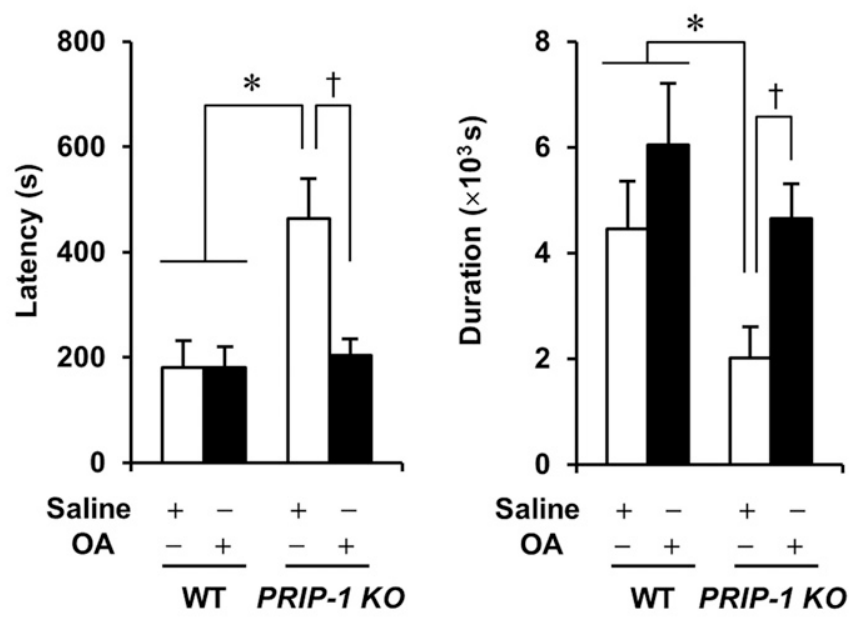

B $O A 0.1 \mathrm{mg} / \mathrm{kg}$ i.p. + Etomidate $30 \mathrm{mg} / \mathrm{kg}$ i.p.
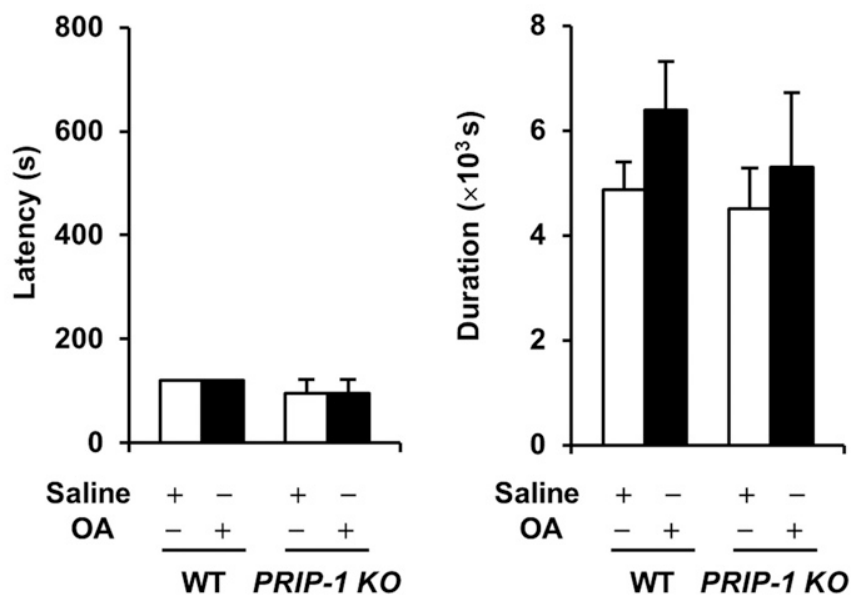

Fig. 3. Effect of OA pretreatment on hypnosis induced by propofol and etomidate in PRIP-1 KO and WT mice. (A) Latency and duration of propofol-induced LORR. Pretreatment with OA shortened the latency and extended the duration of LORR in PRIP-1 KO mice (latency: one-way ANOVA, $F_{3,26}=9.13, P<0.001$, Cohen's $f=1.03$; duration: $F_{3,26}=7.14$, $P<0.01, f=0.91$ ). (B) Latency and duration of etomidate-induced LORR. There were no significant differences in etomidate-induced LORR in either genotype after preinjection with OA (latency: $F_{3,11}=2.86, P>0.05$, $f=0.33$; duration: $\mathrm{F}_{3,11}=0.39, P>0.05, f=0.40$ ). Group $n \geq 4$ mice. Tukey's post hoc comparison: $* P<0.05$, Cohen's $d>1.50$, versus WT mice; ${ }^{\dagger} P<0.05, d>1.60$, versus $P R I P-1 K O$ mice pretreated with saline. Data are mean \pm S.E.M.

phosphorylated $\beta 3$ levels in PRIP-1 KO mice were higher ( $\sim 2$-fold) than those in saline-injected PRIP-1 KO mice.

\section{Discussion}

etomidate, and pentobarbital. (A) Time course and magnitude of propofolinduced LTWR. Significant reduction of percentage of MPE and AUC were observed in PRIP-1 KO mice (unpaired $t$ test: $\%$ MPE at 60 minutes, $\mathrm{t}_{15}=$ $2.30, P<0.05$, Cohen's $d=1.12$; AUC, $\mathrm{t}_{15}=2.25, P<0.05, d=1.10$ ). (B, C) There were no significant differences in LTWR produced by etomidate or pentobarbital between WT and PRIP-1 KO mice (etomidate: AUC, $\mathrm{t}_{15}=$ $0.82, P>0.05, d=0.40$; pentobarbital: AUC, $\mathrm{t}_{9}=0.49, P>0.05, d=0.27$ ). Group $n \geq 6$ mice. ${ }^{*} P<0.05$ versus WT mice. Data are mean \pm S.E.M.

membrane $\mathrm{GABA}_{\mathrm{A}}-\mathrm{R} \beta 3$ subunit in i.p. and i.c.v. salineadministered PRIP-1 KO mice tended to be lower than in WT mice (Fig. 4D). After i.p. or i.c.v. OA injections,

In this study, we found that a lack of PRIP-1 attenuated the hypnotic and immobilizing effects of propofol but not etomidate or pentobarbital. Intraperitoneal pretreatment with OA rescued hypnotic effect of propofol in PRIP-1 $K O$ mice whereas OA did not alter the effect of propofol in WT mice. Furthermore, we confirmed that the dephosphorylated state of the $\mathrm{GABA}_{\mathrm{A}}-\mathrm{R} \beta 3$ subunit in PRIP-1 KO mice was recovered by i.p. OA administration, similar to i.c.v. administration. 
TABLE 2

Effects of OA on anesthetic-induced TAS and LORR in WT and PRIP-1 KO mice

\begin{tabular}{|c|c|c|c|c|c|c|c|}
\hline \multirow{2}{*}{ Anesthetic } & \multirow{2}{*}{ Dose } & \multirow{2}{*}{ OA Dose } & \multicolumn{2}{|r|}{ WT } & \multicolumn{2}{|c|}{ PRIP-1 KO } & \multirow{2}{*}{ Effect Size } \\
\hline & & & $n^{a}$ & TAS $^{b}$ & $n^{a}$ & TAS $^{b}$ & \\
\hline \multicolumn{8}{|c|}{$m g / k g$} \\
\hline Propofol & 140 & 0 & $6 / 6$ & $121(68-151)$ & $7 / 8$ & $38.5(3-99)^{c}$ & $1.59^{d}$ \\
\hline \multirow{3}{*}{ Etomidate } & 140 & 0.1 & $6 / 6$ & $169.5(106-179)$ & $11 / 12$ & $148(30-175)^{e}$ & $0.87,^{d} 1.33^{f}$ \\
\hline & 30 & 0 & $4 / 4$ & $112(110-149)$ & $5 / 5$ & $110(89-177)$ & $0.92^{d}$ \\
\hline & 30 & 0.1 & $4 / 4$ & $179(99-181)$ & $5 / 5$ & $166(16-180)$ & $0.70,^{d} 0.79^{f}$ \\
\hline
\end{tabular}

${ }^{a}$ Denominators represent the number of animals tested in each group. Numerators represent animals that showed LORR.

${ }^{b_{\text {TAS }}}$ express the sum of anesthetic scores as median (range).

${ }^{c} P<0.05$ versus WT mice with the same treatments.

${ }^{d}$ Effect size (Cohen's $d$ ) for TAS compared with WT mice with the same treatment.

${ }^{e} P<0.05$ versus $P R I P-1 K O$ mice pretreated with $\mathrm{OA}(0 \mathrm{mg} / \mathrm{kg})(\mathrm{Mann}-$ Whitney $U$ test $)$.

$f_{\text {Cohen's }} d$ for TAS compared with PRIP-1 KO mice pretreated with OA $(0 \mathrm{mg} / \mathrm{kg})$.

Propofol mainly exerts its anesthetic action via the $\mathrm{GABA}_{\mathrm{A}}-\mathrm{R} \beta 3$ subunit (Jurd et al., 2003; Feng and Macdonald, 2004; Belelli et al., 2005; Drexler et al., 2009). Etomidate potentiates $\mathrm{GABA}_{\mathrm{A}}-\mathrm{R}$ containing $\beta 3$ or $\beta 2$ subunits (Reynolds et al., 2003; Belelli et al., 2005; Drexler et al., 2009). Our current and previous studies have shown that PRIP-1 deficiency reduces $\beta 3$ subunit membrane expression and induces its dephosphorylation (Fig. 4; Zhu et al., 2012). This is because a lack of PRIP-1 induces PP1/2A activation and AP2-clathrinmediated internalization (Terunuma et al., 2004; Kittler et al., 2005; Kanematsu et al., 2007). However, in this study, the total expression level of $\beta 2 / 3$ subunits in PRIP- 1 KO mice did not seem to differ from that of WT mice, suggesting that the reduction in $\beta 3$ subunit membrane expression might be compensated by the $\beta 2$ subunit.

Propofol affinity for the open state of $\alpha 1 \beta 2 \gamma 2 \mathrm{~L} \mathrm{GABA}_{\mathrm{A}}-\mathrm{R}$ is approximately 3- to 7-fold weaker than etomidate (Rüsch et al., 2004; Ruesch et al., 2012). In addition to the $\beta 3$ subunit, $\alpha 1 / 4$ and $\beta 2 \mathrm{GABA}_{\mathrm{A}}-\mathrm{R}$ subunits may be responsible for pentobarbital anesthesia (Zeller et al., 2007; Mercado and Czajkowski, 2008). This evidence suggests that nonsignificant but moderate effective changes of etomidate- and pentobarbital-anesthesia in PRIP-1 KO mice would be because of membrane expression of $\beta 2$-containing $\mathrm{GABA}_{\mathrm{A}}-\mathrm{R}$. There is a possibility that down-regulation of $\beta 3$-containing $\mathrm{GABA}_{\mathrm{A}}-\mathrm{R}$ in cell surface attenuates propofol anesthesia.

Tonic inhibition mediated by extrasynaptic $\mathrm{GABA}_{\mathrm{A}}-\mathrm{R}$ activity is more likely to be involved in anesthetic action than phasic inhibition mediated by synaptic activity (Akk et al., 2004; Bieda and MacIver, 2004; Belelli et al., 2009; Bieda et al., 2009; Kubo et al., 2009; Herd et al., 2014). Extrasynaptic $\mathrm{GABA}_{\mathrm{A}}-\mathrm{R}$ activity partly depends on receptor phosphorylation by various kinases such as protein kinase $A$ and protein kinase $\mathrm{C}$ (Comenencia-Ortiz et al., 2014). For example, protein kinase C-induced phosphorylation of $\alpha 4 \beta 3$ subunits, which mediate tonic inhibition, stabilizes $\mathrm{GABA}_{\mathrm{A}}-\mathrm{R}$ in the cell surface. Consequently, phosphorylated $\mathrm{GABA}_{\mathrm{A}}-\mathrm{R}$ causes enhancement of GABA-mediated currents (Abramian et al., 2010). In contrast, dephosphorylation of the $\beta 3$ subunit by PP1/2A triggers AP2-clathrin-dependent internalization (Terunuma et al., 2004; Kittler et al., 2005; Kanematsu et al., 2007), probably resulting in the reduction of GABA-mediated currents.

Our current and previous studies revealed that PRIP-1 deficiency reduces expression levels of both total and phosphorylated
$\mathrm{GABA}_{\mathrm{A}}-\mathrm{R} \beta 3$ subunit in membrane fraction (Fig. 4; Terunuma et al., 2004; Zhu et al., 2012). Functionally, PRIP-1 deficiency reduces basal tonic currents but not phasic currents in hippocampal and cortical neurons (Zhu et al., 2012). Therefore, PRIP-1 could modulate extrasynaptic $\mathrm{GABA}_{\mathrm{A}}-\mathrm{R}$ activity by preserving the $\beta 3$ subunit phosphorylation state and/or by regulating PP1/2A phosphatase activity. PRIP-1 might be involved in the induction and maintenance of propofol-induced anesthesia through the trafficking of $\mathrm{GABA}_{\mathrm{A}}-\mathrm{R}$ and phosphorylation state of $\mathrm{GABA}_{\mathrm{A}}-\mathrm{R} \beta 3$ subunit.

Contrary to our finding that PRIP-1 deficiency induced dephosphorylation of the GABA $A_{A}-R \beta 3$ subunit in the frontal cortex, another study has reported that phosphorylation levels of the $\beta 3$ subunit in the hippocampus in PRIP-1 KO mice are similar to those of WT mice (Terunuma et al., 2004). This discrepancy may be because of differences in the brain region of interest or in the experimental methods used (crude versus immunoprecipitated protein samples). However, the same study also reported that, in PRIP-1 KO mice, PP1 rather than PP2A phosphatase activity is enhanced and PP1/2A inhibitors partially regain phosphorylation and function of the $\beta 3$ subunit (Terunuma et al., 2004), which supports our i.p. and i.c.v. observations.

Decreased PP1 activity in OA-treated PRIP-1 KO mice is thought to lead to phosphorylation of the $\beta 3$ subunit. Inhibition of PP2A function by OA injection may also contribute to phosphorylation of the $\beta 3$ subunit because OA has a higher affinity to PP2A than PP1 (Chen et al., 1994). PP2A regulates basal levels of $\beta 3$ subunit phosphorylation (Jovanovic et al., 2004). As mentioned earlier, preservation of $\beta 3$ subunit phosphorylation increases cell surface expression levels of $\beta 3$-containing $\mathrm{GABA}_{\mathrm{A}}-\mathrm{R}$ and GABAergic inhibitory transmissions (Abramian et al., 2010; Comenencia-Ortiz et al., 2014). OA pretreatment in PRIP-1 KO mice enhanced the induction and maintenance of hypnosis induced by propofol more effectively than etomidate, suggesting that enhancement of $\beta 3$ subunit phosphorylation by blocking PP1/2A activation increases surface expression of $\beta 3$-containing $\mathrm{GABA}_{\mathrm{A}}-\mathrm{R}$ in PRIP-1 KO mice.

In WT mice, OA pretreatment induced slight, but not statistically significant, increases in anesthetic duration provided by propofol or etomidate. Inhibition of dephosphorylation by OA might induce opposite effect of propofol and etomidate in WT mice. Relatively increased phosphorylation of PRIP-1 by OA may liberate the active form of PP1, leading 
A whole cell

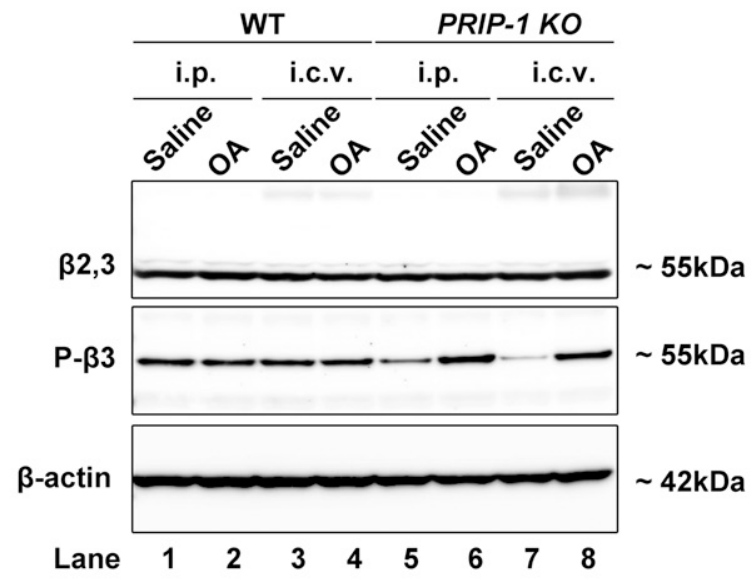

B Membrane fraction

WT

PRIP-1 KO

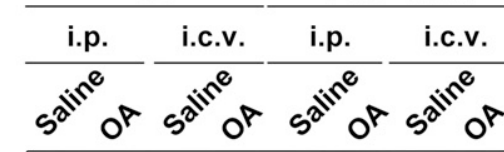

$\beta 3$

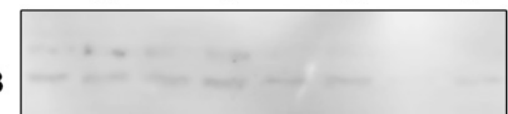

$\sim 52 \mathrm{kDa}$

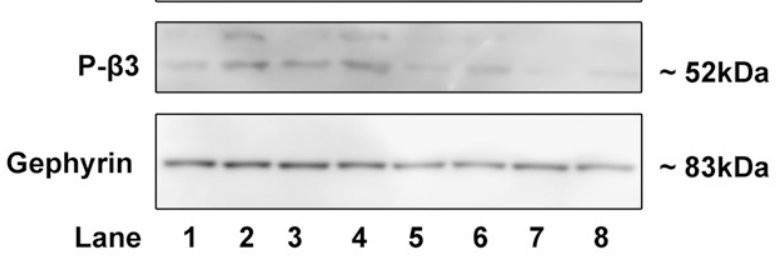

C GABA $_{A}-R \beta 3$ subunit

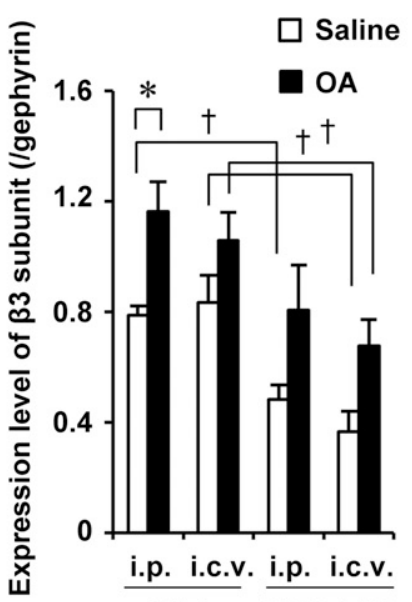

WT PRIP-1 KO to activation of PP2A (Sugiyama et al., 2012). It is possible to inhibit the hypnotic effect of propofol and etomidate. In contrast, blockade of PP1/2A phosphatase activity by OA may provide potentiation of propofol and etomidate action in WT mice. Taken together, in our present study, administration of OA in WT mice provide slight potentiation of propofol and etomidate action.

Study Limitations. The anesthetics administered i.p. in this study are usually given via intravenous bolus injection or continuous infusion in humans and large animals, so the current results from i.p. administration in the mouse should be interpreted with caution. We could not analyze the effects of PRIP-1 deficiency on membrane expression and phosphorylation of $\mathrm{GABA}_{\mathrm{A}}-\mathrm{R} \alpha 1-6, \beta 1 / 2, \gamma 1-3$, and $\delta$ subunits. These subunit complexes play important roles in receptor phosphorylation, phasic/tonic inhibition, and endocytosis (Belelli et al., 2009; Comenencia-Ortiz et al., 2014). The effects of phosphorylation on $\mathrm{GABA}_{\mathrm{A}}-\mathrm{R}$ are diverse and appear to be highly dependent on the subunit composition (Terunuma et al., 2004; Kittler et al., 2005; Yanagihori et al., 2006; Abramian et al., 2010; Comenencia-Ortiz et al., 2014). Therefore, our current data would be but a part of the interaction among anesthetics, $\mathrm{GABA}_{\mathrm{A}}-\mathrm{R}$ phosphorylation, and its regulatory protein PRIP-1. Further studies are required to provide comprehensive mechanisms behind the effects of PRIP-1 deficiency on anesthetic action.

\section{Conclusions}

We found that the PRIP-1-mediated GABA $_{A}-\mathrm{R}$ phosphorylation state is important for the induction of and emergence from propofol-induced anesthesia. Enhancement of $\mathrm{GABA}_{\mathrm{A}}-\mathrm{R}$ phosphorylation could potentiate propofol anesthesia. Although there might be various technical difficulties, our data imply the anesthetic and/or therapeutic possibility of $\mathrm{GABA}_{\mathrm{A}}-\mathrm{R}$ phospho-regulation. The preoperative estimation of the $\mathrm{GABA}_{\mathrm{A}}-\mathrm{R}$ phosphorylation state and its regulatory protein activity, such as PRIP-1, PP1/2A, or protein kinase $\mathrm{C}$, in a patient would suggest a better propofol and/or other anesthetic administration plan to prevent adverse events such as awakening during and delayed emergence from anesthesia. PRIP-1 and other proteins involved in $\mathrm{GABA}_{\mathrm{A}}-\mathrm{R}$

The band intensity was normalized to gephyrin. (C, D) The results of Western blotting of the membrane fraction are represented in a graph. (C) Membrane expression of the $\beta 3$ subunit in PRIP-1 KO mice significantly decreased compared with WT mice (i.p. treatment: unpaired $t$ test, $\mathrm{t}_{4}=4.87$, $P<0.05$, Cohen's $d=3.98$; i.c.v. treatment: $\mathrm{t}_{4}=3.81, P<0.05, d=3.11$ ). OA treatment induced increases in surface $\beta 3$ subunit expression levels in both genotypes (WT: i.p.: $\mathrm{t}_{4}=3.28, P<0.05, d=2.68$; i.c.v.: $\mathrm{t}_{4}=1.60, P=0.18, d=$ $1.31 ; P R I P-1 K O$ : i.p.: $\mathrm{t}_{4}=1.90, P=0.13, d=1.55$; i.c.v.: $\mathrm{t}_{4}=2.57, P=0.06, d=$ 2.10 ). Slight differences were detected in $\beta 3$ membrane expression levels between WT and PRIP-1 KO mice administered OA (i.p.: $\mathrm{t}_{4}=1.82, P=0.14$ $d=1.49$; i.c.v.: $\mathrm{t}_{4}=2.78, P<0.05, d=2.27$ ). (D) Surface P- $\beta 3$ expression in $P R I P-1 \mathrm{KO}$ mice tended to be lower than that in WT mice (i.p.: $\mathrm{t}_{4}=0.75, P=$ $0.49, d=0.61$; i.c.v.: $\left.\mathrm{t}_{4}=6.45, P<0.05, d=2.27\right)$. OA administration enhanced membrane P- $\beta 3$ subunit levels in WT and PRIP-1 KO mice (WT: i.p.: $\mathrm{t}_{4}=1.89, P=0.13, d=1.53$; i.c.v.: $\mathrm{t}_{4}=0.64, P=0.56, d=0.52 ; P R I P-1 \mathrm{KO}$ : i.p.: $\mathrm{t}_{4}=2.72, P=0.05, d=2.22$; i.c.v.: $\mathrm{t}_{4}=2.40, P=0.07, d=1.96$ ). Membrane $\mathrm{P}-\beta 3$ subunit levels were comparable between genotypes treated with $\mathrm{OA}$ (i.p.: $\mathrm{t}_{4}=0.93, P=0.41, d=0.76$; i.c.v.: $\mathrm{t}_{4}=0.25, P=0.82, d=0.20$ ). ${ }^{*} P<0.05$, Cohen's $d=2.68$, versus mice treated with saline; ${ }^{\dagger} P<0.05, d \geq 2.27$ versus WT mice with the same treatments. Data are mean \pm S.E.M. 
phosphorylation and membrane trafficking may emerge as novel candidates for agent-specific regulatory factors in the control of anesthetic action.

\section{Acknowledgments}

The authors thank Noriaki Kawai for technical assistance.

\section{Authorship Contributions}

Participated in research design: Yoshikazu, Tetsuya, Kazuyoshi,

Shinya.

Conducted experiments: Yoshikazu, Tomonori, Shuji.

Performed data analysis: Yoshikazu, Tomonori, Shuji, Shinya.

Wrote or contributed to the writing of the manuscript: Yoshikazu, Tomonori, Shuji, Junko, Keisuke, Kohei, Tetsuya, Kazuyoshi, Takashi, Masato, Shinya.

\section{References}

Abramian AM, Comenencia-Ortiz E, Vithlani M, Tretter EV, Sieghart W, Davies PA and Moss SJ (2010) Protein kinase C phosphorylation regulates membrane in sertion of $\mathrm{GABA}_{\mathrm{A}}$ receptor subtypes that mediate tonic inhibition. $J$ Biol Chem 285:41795-41805.

Akk G, Bracamontes J, and Steinbach JH (2004) Activation of $\operatorname{GABA}_{\mathrm{A}}$ ) receptors containing the $\alpha 4$ subunit by GABA and pentobarbital. $J$ Physiol 556:387-399.

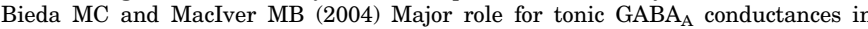
anesthetic suppression of intrinsic neuronal excitability. $J$ Neurophysiol 92: 1658-1667.

Bieda MC, Su H, and Maciver MB (2009) Anesthetics discriminate between tonic and phasic gamma-aminobutyric acid receptors on hippocampal CA1 neurons. Anesth Analg 108:484-490.

Belelli D, Peden DR, Rosahl TW, Wafford KA, and Lambert JJ (2005) Extrasynaptic $\mathrm{GABA}_{\mathrm{A}}$ receptors of thalamocortical neurons: a molecular target for hypnotics. $J$ Neurosci 25:11513-11520.

Belelli D, Harrison NL, Maguire J, Macdonald RL, Walker MC, and Cope DW (2009) Extrasynaptic $\mathrm{GABA}_{\mathrm{A}}$ receptors: form, pharmacology, and function. $J$ Neurosci 29 : 12757-12763.

Chen MX, McPartlin AE, Brown L, Chen YH, Barker HM, and Cohen PT (1994) A novel human protein serine/threonine phosphatase, which possesses four tetratricopeptide repeat motifs and localizes to the nucleus. EMBO J 13:4278-4290.

Cohen J (1992) A power primer. Psychol Bull 112:155-159.

Comenencia-Ortiz E, Moss SJ, and Davies PA (2014) Phosphorylation of GABA receptors influences receptor trafficking and neurosteroid actions. Psychophar macology (Berl) 231:3453-3465.

Del Re AC (2013) compute.es: Compute Effect Sizes. R package version 0.2-2. http:// CRAN.R-project.org/package $=$ compute.es

Drexler B, Jurd R, Rudolph U, and Antkowiak B (2009) Distinct actions of etomidate and propofol at $\beta 3$-containing gamma-aminobutyric acid type A receptors. Neuropharmacology 57:446-455.

Feng HJ and Macdonald RL (2004) Multiple actions of propofol on $\alpha \beta \gamma$ and $\alpha \beta \delta$ $\mathrm{GABA}_{\mathrm{A}}$ receptors. Mol Pharmacol 66:1517-1524.

Fujii M, Kanematsu T, Ishibashi H, Fukami K, Takenawa T, Nakayama KI, Moss SJ, Nabekura J, and Hirata M (2010) Phospholipase C-related but catalytically inactive protein is required for insulin-induced cell surface expression of $\gamma$-aminobutyric acid type A receptors. $J$ Biol Chem 285:4837-4846.

Garção P, Oliveira CR, Cunha RA, and Agostinho P (2014) Subsynaptic localization of nicotinic acetylcholine receptor subunits: a comparative study in the mouse and rat striatum. Neurosci Lett 566:106-110.

Goebel-Goody SM, Davies KD, Alvestad Linger RM, Freund RK, and Browning MD (2009) Phospho-regulation of synaptic and extrasynaptic $N$-methyl-D-aspartate receptors in adult hippocampal slices. Neuroscience 158:1446-1459.

Herd MB, Lambert JJ, and Belelli D (2014) The general anaesthetic etomidate inhibits the excitability of mouse thalamocortical relay neurons by modulating multiple modes of GABA receptor-mediated inhibition. Eur $J$ Neurosci 40:2487-2501.

Irifune M, Takarada T, Shimizu Y, Endo C, Katayama S, Dohi T, and Kawahara M (2003) Propofol-induced anesthesia in mice is mediated by $\gamma$-aminobutyric acid-A and excitatory amino acid receptors. Anesth Analg 97:424-429.

Jovanovic JN, Thomas P, Kittler JT, Smart TG, and Moss SJ (2004) Brain-derived neurotrophic factor modulates fast synaptic inhibition by regulating $\mathrm{GABA}(\mathrm{A}) \mathrm{re}$ ceptor phosphorylation, activity, and cell-surface stability. $J$ Neurosci 24:522-530.

Jurd R, Arras M, Lambert S, Drexler B, Siegwart R, Crestani F, Zaugg M, Vogt KE, Ledermann B, Antkowiak B, et al. (2003) General anesthetic actions in vivo strongly attenuated by a point mutation in the $\left.\operatorname{GABA}_{\mathrm{A}}\right)$ receptor $\beta 3$ subunit. FASEB J 17:250-252.

Kanematsu T, Fujii M, Mizokami A, Kittler JT, Nabekura J, Moss SJ, and Hirata M (2007) Phospholipase C-related inactive protein is implicated in the constitutive internalization of $\mathrm{GABA}_{\triangle}$ receptors mediated by clathrin and AP2 adaptor complex. J Neurochem 101:898-905.

Kanematsu T, Jang IS, Yamaguchi T, Nagahama H, Yoshimura K, Hidaka K, Matsuda M, Takeuchi H, Misumi Y, Nakayama K, et al. (2002) Role of the PLC-related, catalytically inactive protein p130 in $\left.\operatorname{GABA}_{\mathrm{A}}\right)$ receptor function. $E M B O J$ 21:1004-1011.

Kanematsu T, Misumi Y, Watanabe Y, Ozaki S, Koga T, Iwanaga S, Ikehara Y, and Hirata M (1996) A new inositol 1,4,5-trisphosphate binding protein similar to phospholipase C-delta 1. Biochem J 313:319-325.
Kanematsu T, Takeya H, Watanabe Y, Ozaki S, Yoshida M, Koga T, Iwanaga S, and Hirata M (1992) Putative inositol 1,4,5-trisphosphate binding proteins in rat brain cytosol. J Biol Chem 267:6518-6525.

Kanematsu T, Yasunaga A, Mizoguchi Y, Kuratani A, Kittler JT, Jovanovic JN, Takenaka K, Nakayama KI, Fukami K, Takenawa T, et al. (2006) Modulation of $\left.\mathrm{GABA}_{\mathrm{A}}\right)$ receptor phosphorylation and membrane trafficking by phospholipase C-related inactive protein/protein phosphatase 1 and $2 \mathrm{~A}$ signaling complex underlying brain-derived neurotrophic factor-dependent regulation of GABAergic inhibition. J Biol Chem 281:22180-22189.

Kittler JT, Chen G, Honing S, Bogdanov Y, McAinsh K, Arancibia-Carcamo IL Jovanovic JN, Pangalos MN, Haucke V, Yan Z, et al. (2005) Phospho-dependent binding of the clathrin AP2 adaptor complex to $\mathrm{GABA}_{\mathrm{A}}$ receptors regulates the efficacy of inhibitory synaptic transmission. Proc Natl Acad Sci USA 102:14871-14876. Kubo K, Nishikawa K, Hardy-Yamada M, Ishizeki J, Yanagawa Y, and Saito S (2009) Altered responses to propofol, but not ketamine, in mice deficient in the 65-kilodalton isoform of glutamate decarboxylase. J Pharmacol Exp Ther 329:592-599.

Matsuda M, Kanematsu T, Takeuchi H, Kukita T, and Hirata M (1998) Localization of a novel inositol 1,4,5-trisphosphate binding protein, p130 in rat brain. Neurosci Lett 257:97-100.

Maeda T, Hamabe W, Gao Y, Fukazawa Y, Kumamoto K, Ozaki M, and Kishioka S (2005) Morphine has an antinociceptive effect through activation of the okadaicacid-sensitive Ser/Thr protein phosphatases PP 2 A and PP5 estimated by tailpinch test in mice. Brain Res 1056:191-199.

Mercado J and Czajkowski C (2008) Gamma-aminobutyric acid (GABA) and pentobarbital induce different conformational rearrangements in the GABA receptor $\alpha 1$ and $\beta 2$ pre-M1 regions. J Biol Chem 283:15250-15257.

Migita K, Tomiyama M, Yamada J, Fukuzawa M, Kanematsu T, Hirata M, and Ueno S (2011) Phenotypes of pain behavior in phospholipase C-related but catalytically inactive protein type 1 knockout mice. Mol Pain 7:79.

Mizokami A, Kanematsu T, Ishibashi H, Yamaguchi T, Tanida I, Takenaka K, Nakayama KI, Fukami K, Takenawa T, Kominami E, et al. (2007) Phospholipase C-related inactive protein is involved in trafficking of $\gamma 2$ subunit-containing GABA (A) receptors to the cell surface. $J$ Neurosci 27:1692-1701.

Ozaki T, Nakazawa M, Yamashita T, Sorimachi H, Hata S, Tomita H, Isago H, Baba $\mathrm{A}$, and Ishiguro S (2012) Intravitreal injection or topical eye-drop application of a $\mu$-calpain C2L domain peptide protects against photoreceptor cell death in Royal College of Surgeons' rats, a model of retinitis pigmentosa. Biochim Biophys Acta 1822:1783-1795.

Paxinos G and Franklin KB (2001) The Mouse Brain in Stereotaxic Coordinates, 2nd ed. Academic Press, San Diego.

R Core Team(2016) R: A language and environment for statistical computing. R Foundation for Statistical Computing, Vienna, Austria. https://www.R-project.org/.

Reynolds DS, Rosahl TW, Cirone J, O'Meara GF, Haythornthwaite A, Newman RJ, Myers J, Sur C, Howell O, Rutter AR, et al. (2003) Sedation and anesthesia mediated by distinct GABA(A) receptor isoforms. J Neurosci 23:8608-8617.

Rudolph U and Antkowiak B (2004) Molecular and neuronal substrates for general anaesthetics. Nat Rev Neurosci 5:709-720.

Rüsch D, Zhong H, and Forman SA (2004) Gating allosterism at a single class of etomidate sites on $\alpha 1 \beta 2 \gamma 2 \mathrm{~L}$ GABA A receptors accounts for both direct activation and agonist modulation. J Biol Chem 279:20982-20992.

Ruesch D, Neumann E, Wulf H, and Forman SA (2012) An allosteric coagonist model for propofol effects on $\alpha 1 \beta 2 \gamma 2 \mathrm{~L} \gamma$-aminobutyric acid type A receptors. Anesthesiology 116:47-55.

Semyanov A, Walker MC, Kullmann DM, and Silver RA (2004) Tonically active GABA A receptors: modulating gain and maintaining the tone. Trends Neurosci 27:262-269.

Sugiyama G, Takeuchi H, Nagano K, Gao J, Ohyama Y, Mori Y, and Hirata M (2012) Regulated interaction of protein phosphatase 1 and protein phosphatase 2A with phospholipase C-related but catalytically inactive protein. Biochemistry 51:3394-3403. Tubaro A, Sosa S, Carbonatto M, Altinier G, Vita F, Melato M, Satake M, and Yasumoto T (2003) Oral and intraperitoneal acute toxicity studies of yessotoxin and homoyessotoxins in mice. Toxicon 41:783-792.

Terunuma M, Jang IS, Ha SH, Kittler JT, Kanematsu T, Jovanovic JN, Nakayama KI, Akaike N, Ryu SH, Moss SJ, et al. (2004) GABA A receptor phospho-dependent modulation is regulated by phospholipase C-related inactive protein type 1 , a novel protein phosphatase 1 anchoring protein. $J$ Neurosci 24:7074-7084.

Venables WN and Ripley BD (2002) Modern Applied Statistics with S, 4th ed. Springer, New York

Yanagihori S, Terunuma M, Koyano K, Kanematsu T, Ho Ryu S, and Hirata M (2006) Protein phosphatase regulation by PRIP, a PLC-related catalytically inactive protein-implications in the phospho-modulation of the GABA receptor. Adv Enzyme Regul 46:203-222.

Yoshimura K, Takeuchi H, Sato O, Hidaka K, Doira N, Terumura M, Harada K, Ogawa Y, Ito Y, Kanematsu T, and Hirata M (2001) Interaction of p130 with, and consequent inhibition of, the catalytic subunit of protein phosphatase $1 \alpha$. J Biol Chem 276: 17908-13.

Zeller A, Arras M, Jurd R, and Rudolph U (2007) Identification of a molecular target mediating the general anesthetic actions of pentobarbital. Mol Pharmacol 71:852-859. Zhu G, Yoshida S, Migita K, Yamada J, Mori F, Tomiyama M, Wakabayashi K, Kanematsu T, Hirata M, Kaneko S, et al. (2012) Dysfunction of extrasynaptic GABAergic transmission in phospholipase C-related, but catalytically inactive protein 1 knockout mice is associated with an epilepsy phenotype. $J$ Pharmacol Exp Ther 340:520-528.

Address correspondence to: Dr. Shinya Ueno, Department of Neurophysiology, Hirosaki University Graduate School of Medicine, 5 Zaifu-cho, Hirosaki, Aomori 036-8562, Japan. E-mail: shinyau@hirosaki-u.ac.jp 